\title{
Efficacy and Safety of Ombitasvir/Paritaprevir/Ritonavir and Dasabuvir \pm Ribavirin for HCV in Brazilian Adults with Advanced Fibrosis
}

Mario G. Pessoa, ${ }^{*}$ José V. Ramalho-Madruga, ${ }^{\dagger}$ Katia Alves, ${ }^{\ddagger}$ Estevão P. Nunes,, Hugo Cheinquer," Carlos E. Brandão-Mello, " Maria C. Mendes-Correa, ${ }^{* *}$ Maria L. Ferraz, ${ }^{\dagger \dagger}$ Paulo R. A. Ferreira, Mário R. Álvares-da-Silva, ${ }^{\S}$ Henrique S. Coelho, Giovanni Silva, ${ }^{\ddagger} \neq$ Sara A. Lari, ${ }^{\ddagger}$ Li Liu, ${ }^{\ddagger}$ Rakesh Tripathi, ${ }^{\ddagger}$ Tami Pilot-Matias, ${ }^{\ddagger}$ Daniel E. Cohen,${ }^{\ddagger}$ Nancy S. Shulman, ${ }^{\ddagger}$ Ana Martinelli§§\&

* Division of Gastroenterology and Hepatology, University of São Paulo School of Medicine, São Paulo, Brazil. $\dagger$ Centro de Referência e Treinamento DST/AIDS, São Paulo, Brazil.

‡ AbbVie Inc., North Chicago, Illinois, United States. $\S$ National Institute of Infectious Diseases/FIOCRUZ, Brazil.

I Universidade Federal de Rio Grande de Sul, Gastroenterology and Hepatology Unit, Hospital de Clinicas de Porto Alegre, Brazil. II Internal Medicine Department, College of Medicine \& Surgery, Universidade Federal do Estado do Rio de Janeiro - UNIRIO, Rio de Janeiro, Brazil.

** Department of Infectious Diseases, São Paulo University Medical School, University of São Paulo, Brazil. t† Department of Gastroenterology, Escola Paulista de Medicina, UNIFESP, São Paulo, Brazil.

¥ Department of Infectious Diseases, Federal University of São Paulo, São Paulo, Brazil. $\$ \S$ Universidade Federal do Rio Grande do Sul, Porto Alegre, Brazil Graduate Program in Gastroenterology and Hepatology Sciences. IIII Servicio de Hepatologia, Departamento de Clinica Medica, Universidade Federal do Rio de Janeiro (UFRJ), Rio de Janeiro, Brazil. If University of São Paulo Hospital das Clínicas, Infectious Diseases Department-Hepatitis Unit, São Paulo, Brazil. *** UGA I - Hospital Heliópolis; São Paulo, Brazil. t†† Universidade Federal da Bahia, Ambulatório Magalhães Neto, HUPES-UFBA, Salvador-BA, Brazil. $\ddagger \neq \ddagger$ Botucatu School of Medicine - UNESP; Botucatu, Brazil. $\S \S \S$ Department of Medicine, Gastroenterology Division, Ribeirao Preto School of Medicine, University of São Paulo, Brazil.

\section{ABSTRACT}

Introduction and aim. Approximately 650,000 people in Brazil have chronic hepatitis $\mathrm{C}$ virus (HCV) infection. We evaluated the safety and efficacy of ombitasvir (OBV)/paritaprevir (PTV)/ritonavir ( $r$ ) plus dasabuvir (DSV) with/without ribavirin (RBV) in an openlabel multicenter phase $3 \mathrm{~b}$ trial in treatment-naive or interferon (IFN) treatment-experienced Brazilian patients with advanced hepatic fibrosis (METAVIR F3/4) and HCV genotype (GT) 1 infection. Material and methods. All patients received coformulated OBV/ PTV/r daily + DSV twice daily (3-DAA). GT1a-infected patients received 3-DAA plus RBV for 12 weeks, except for prior pegIFN/ RBV nonresponders with cirrhosis who were treated for 24 weeks. GT1b-infected patients received 3-DAA alone (F3) or in combination with RBV (F4) for 12 weeks. The primary endpoint was sustained virologic response (HCV RNA $<15 \mathrm{IU} / \mathrm{mL}$ ) at post-treatment Week $12\left(\mathrm{SVR}_{12}\right)$. Results. The study enrolled 222 patients, 214 achieved an $\mathrm{SVR}_{12}(96.4 \% ; 95 \% \mathrm{Cl}$, 93.1-98.2\%), one GT1a-infected patient experienced virologic breakthrough, six (5 GT1a) relapsed, and one was lost to follow-up. SVR ${ }_{12}$ was achieved in 111/ $112(99.1 \%)$ GT1b-infected patients, including $42 / 43(97.7 \%)$ noncirrhotic, and 69/69 (100\%) cirrhotic patients; and in 103/110 (93.6\%) GT1a-infected patients, including $44 / 46$ (95.7\%) noncirrhotic and 59/64 (92.2\%) cirrhotic patients. Overall there was a low rate of serious adverse events $(n=6,2.7 \%)$. One patient experienced a treatment-related serious adverse event and one patient discontinued treatment because of an adverse event. Discussion. The results confirm that the 3-DAA regimen with/without RBV is well tolerated and had a favorable safety profile and is efficacious in GT1-infected patients with advanced fibrosis (METAVIR F3/4).

Key words. Chronic hepatits C. Direct-acting antivirals. Genotype 1. Advanced fibrosis. 


\section{INTRODUCTION}

The seroprevalence of chronic hepatitis $\mathrm{C}$ virus (HCV) infection in Brazil is estimated to be approximately $1.38 \%$, translating to currently 650,000 people who require treatment, most of whom are not diagnosed. ${ }^{1-4}$ In 2017, Brazil's universal healthcare system updated its Guideline and now provides free treatment for citizens with chronic hepatitis C including individuals with HIV coinfection, renal insufficiency, idiopathic thrombocytopenic purpura, cryoglobulinemia, hematologic malignancies, solid organ transplant recipients, severe extra-hepatic manifestations, and moderate hepatic fibrosis (METAVIR stages greater than F2 by biopsy or non-invasive methodology). ${ }^{5} \mathrm{HCV}$ genotype (GT) 1 is the most common across all regions of Brazil; 6 thus, a regimen must have good activity against GT1a and GT1b to be suitable for use in this setting.

Across many regions of the world the current standard of care for patients with chronic hepatitis $\mathrm{C}$ involves treatment with combinations of orally administered direct-acting antiviral agents (DAAs)..$^{7-9}$ The combination of ombitasvir (OBV), ritonavir-enhanced paritaprevir (PTV/r; paritaprevir developed by AbbVie and Enanta), and dasabuvir (DSV), with or without weight-based ribavirin (RBV), has demonstrated high rates of sustained virologic response at posttreatment Week $12\left(\mathrm{SVR}_{12}\right)$ in GT1-infected patients without cirrhosis or with compensated cirrhosis, ${ }^{10-15}$ and is one of several regimens recommended for this subset of patients in current treatment guidelines. ${ }^{7-9}$

The objective of this Phase $3 \mathrm{~b}$ study was to evaluate the efficacy and safety of 12 or 24 weeks of treatment with OBV/PTV/r plus DSV (3-DAA) with or without RBV in treatment-naive or interferon (IFN) treatment-experienced, GT1-infected Brazilian patients with advanced hepatic fibrosis (bridging fibrosis or compensated cirrhosis, METAVIR F3-F4).

\section{MATERIAL AND METHODS}

TOPAZ-III (M14-225, clinicaltrials.gov identifier NCT02442271) was a Phase 3b, open-label, multicenter trial that was conducted at 16 sites in Brazil. The study conformed to the Declaration of Helsinki and adhered to International Conference on Harmonization (ICH) guidelines. The protocol and all amendments were approved by independent ethics committees or institutional review boards at each study site. All patients provided written informed consent prior to undergoing any study procedures.

\section{Patients}

Patients eligible for the trial were adults $\geq 18$ years of age with HCV genotype 1 infection, a serum HCV RNA level $>1000 \mathrm{IU} / \mathrm{mL}$ at the time of screening and advanced hepatic fibrosis. Advanced fibrosis was documented by the results of a liver biopsy performed within 24 months prior to receipt of the first dose of study drug (METAVIR F3, Ishak 4, or equivalent); a liver biopsy showing cirrhosis (METAVIR F3/4 or F4, Ishak 5 or 6 , or equivalent) at any time prior to receipt of the first dose of study drug; a FibroScan ${ }^{\circledR}$ result of $\geq 9.6 \mathrm{kPa}$ obtained within 6 months prior to the first dose of study drug; or a FibroTest ${ }^{\circledR}$ result of $\geq 0.59$ obtained during the screening period. Patients with cirrhosis could be included if they had compensated liver disease (Child-Pugh A) with no prior history of hepatic decompensation. Both treatment-naive and IFN-experienced patients were eligible.

Patients with cirrhosis were required to have ultrasound, computed tomography or magnetic resonance imaging within 3 months prior to screening in order to exclude hepatocellular carcinoma.

Patients were excluded if they had a positive screening test result for human immunodeficiency virus or hepatitis B surface antigen. Patients were also ineligible if they had a creatinine clearance $<30 \mathrm{~mL} / \mathrm{min}$, albumin $<2.8 \mathrm{~g} / \mathrm{dL}$, hemoglobin $<10 \mathrm{~g} / \mathrm{dL}$, platelet count $<25 \times 10^{9} / \mathrm{L}$ or a total bilirubin level $>3 \mathrm{mg} / \mathrm{dL}$. Patients who had previously received direct acting antiviral agents were ineligible for the trial.

\section{Treatment}

All patients received oral co-formulated OBV/PTV/r (25/150/100 $\mathrm{mg}$ ) once daily and DSV (250 mg twice daily) with or without RBV $(1,000 \mathrm{mg}$ daily for body weight $<$ $75 \mathrm{~kg}$ or $1,200 \mathrm{mg}$ daily for body weight $\geq 75 \mathrm{~kg}$ ) for 12 or 24 weeks according to HCV GT1 subtype (1a or 1b) and METAVIR fibrosis stage (Figure 1). All noncirrhotic patients (GT1a- and GT1b-infected) and cirrhotic GT1b-infected patients were assigned to 12 weeks of treatment regardless of treatment history (naive or IFN-experienced). Among GT1a-infected patients with cirrhosis, those who were treatment naive, or who had experienced a prior partial virologic response, breakthrough or relapse, or who were intolerant to previous treatment with IFNbased therapy were assigned to 12 weeks of treatment; whereas, GT1a-infected patients with cirrhosis who had experienced a prior nonresponse or null response to previous treatment with IFN-based therapy were assigned to 24 weeks of treatment. All GT1a-infected patients and GT1b-infected patients with cirrhosis received RBV. Noncirrhotic patients with GT1b infection received the regimen without RBV.

All patients who received at least one dose of study drug were followed up for 24 weeks after completion or premature discontinuation of study drug. 


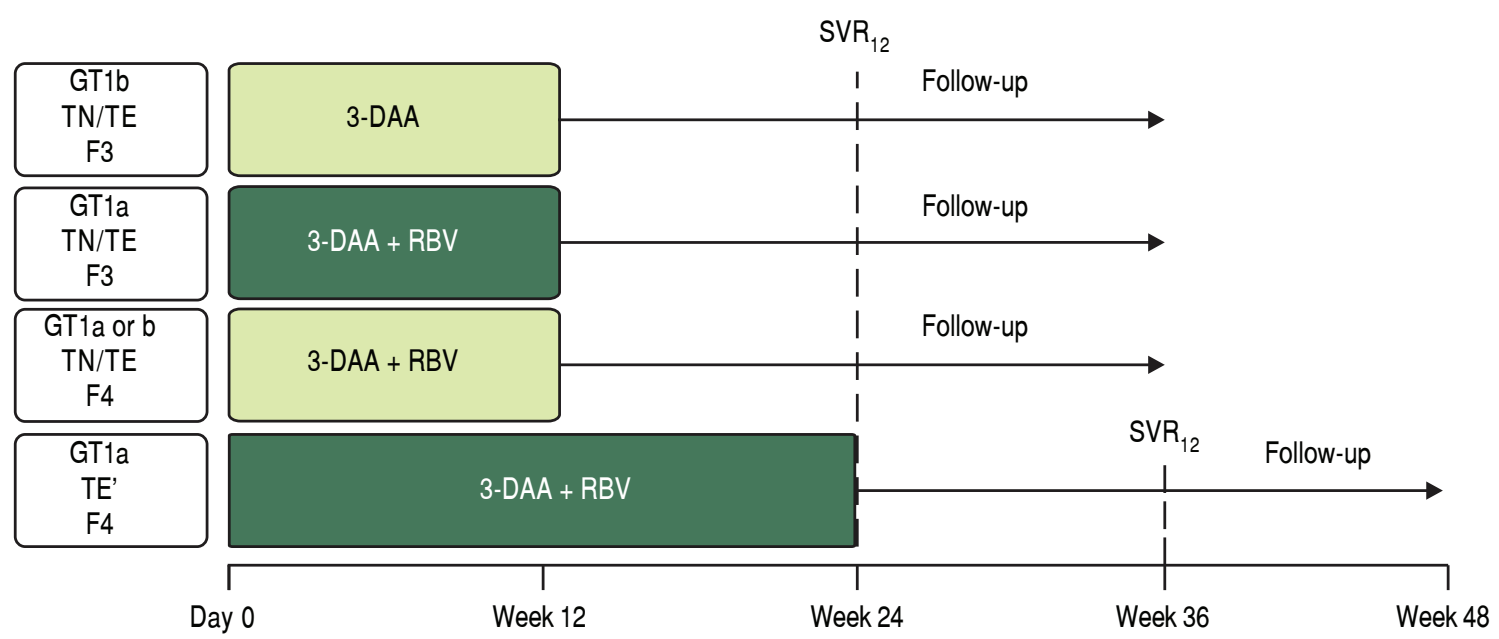

Figure 1. Study Design. * Treatment experienced patients with cirrhosis and GT1a infection and a prior null response or nonresponse were assigned to 24 weeks of treatment. All other patients with cirrhosis were assigned to 12 weeks of treatment. 3-DAA, ombitasvir/paritaprevir/ritonavir 25/150/100 mg once daily + dasabuvir $250 \mathrm{mg}$ twice daily \pm ribavirin (weight-based). TN: treatment-naïve. TE: treatment-experienced (IFN/RBV or pegIFN/RBV experienced patients).

\section{Efficacy and safety assessments}

The primary efficacy endpoint was sustained virologic response (the proportion of patients with HCV RNA below the lower limit of quantification [LLOQ]) at 12 weeks $\left(\mathrm{SVR}_{12}\right)$ after the final dose of study drug. HCV RNA levels in plasma were determined using the COBAS ${ }^{\circledR}$ AmpliPrep/COBAS ${ }^{\circledR}$ Taqman ${ }^{\circledR}$ HCV Test, v. 2.0 $(\mathrm{LLOQ}=15 \mathrm{IU} / \mathrm{mL})$. Secondary efficacy endpoints were $\mathrm{SVR}_{12}$ rates by fibrosis stage, prior treatment experience (naive, or previous IFN-based regimen), and IFN eligibility (ineligible, intolerant, eligible).

Treatment-emergent adverse events (TEAEs) were monitored from initiation of treatment until 30-days after discontinuation of study drugs.

\section{Resistance analyses}

For any patient who experienced virologic failure, $\mathrm{HCV}$ regions encoding NS3/4A, NS5A, and NS5B were amplified by PCR and the resulting PCR products were sequenced by population sequencing (approximately 15\% detection threshold) from the baseline sample and the first sample obtained after virologic failure that had an HCV RNA level $\geq 1000 \mathrm{IU} / \mathrm{mL}$. The resulting sequences were analyzed for the presence of pre-existing baseline polymorphisms and treatment-emergent amino acid substitutions.

\section{Data analyses}

Given a planned enrollment of 220 patients and an estimated SVR12 rate of $95 \%$, the 2 -sided $95 \%$ confidence in- terval (CI) calculated by Wilson's score method will be $91.3 \%$ to $97.2 \%$. No adjustments were made for dropouts. Analyses were performed on the intent-to-treat (ITT) population, which consisted of all patients who received at least one dose of study drug. Patients with missing SVR12 results were considered to be treatment failures.

Safety data were analyzed using descriptive statistics.

\section{RESULTS}

The study enrolled 222 individuals (ITT population), including $59.9 \%(\mathrm{n}=133)$ with cirrhosis $(48.1 \%$ [64/133] and 51.9\% [69/133] with GT1a and GT1b infection, respectively) and $40.1 \%(\mathrm{n}=89)$ noncirrhotic (F3) patients (51.7\% [46/89] and 48.3\% [43/89] with GT1a and GT1b infection, respectively) across 16 study centers in Brazil. The first patient was enrolled on 27 April 2015 and the last patient completed follow-up on 26 September 2016.

The majority of patients were male $(55.4 \%)$, white $(82.4 \%)$, aged $<65$ years $(77.0 \%)$, and had received prior IFN-based therapy (54.1\%) (Table 1). Overall, the median age was 57 years (range 26-78), and the median BMI was $26.5 \mathrm{~kg} / \mathrm{m}^{2}$ (range 17-51).

One cirrhotic patient who was assigned to 12 weeks of treatment with 3-DAA plus RBV prematurely discontinued study drug due to a TEAE; thus, $99.5 \%$ of patients (221/222) completed treatment.

\section{Efficacy}

The $\mathrm{SVR}_{12}$ rate was $96.4 \%(214 / 222 ; 95 \%$ CI, 93.198.2\%) (Figure 2A). Among the 8 patients who did not 
Table 1. Baseline demographic and clinical characteristics.

\begin{tabular}{|c|c|c|c|c|c|}
\hline \multirow[t]{2}{*}{ Characteristics } & \multicolumn{2}{|c|}{ Patients with cirrhosis (F4) } & \multicolumn{2}{|c|}{ Patient without cirrhosis (F3) } & \multirow{2}{*}{$\begin{array}{c}\text { Total } \\
(\mathrm{N}=222)\end{array}$} \\
\hline & $\begin{array}{c}\text { GT1a } \\
\text { 3-DAA+RBV } \\
\times 12 \text { or } 24 \\
\text { weeks } \\
(n=64)\end{array}$ & $\begin{array}{c}\text { GT1b } \\
\text { 3-DAA+RBD } \\
\text { x } 12 \\
\text { weeks } \\
(n=69)\end{array}$ & $\begin{array}{c}\text { GT1a } \\
\text { 3-DAA+RBV } \\
\text { x } 12 \\
\text { weeks } \\
(n=46)\end{array}$ & $\begin{array}{c}\text { GT1b } \\
3 \text {-DAA } \\
\times 12 \\
\text { weeks } \\
(n=43)\end{array}$ & \\
\hline Male sex, $\mathrm{n}(\%)$ & $35(54.7)$ & $35(50.7)$ & $28(60.9)$ & $25(58.1)$ & $123(55.4)$ \\
\hline Age, years, median (range) & $55.5(29-73)$ & $61.0(35-78)$ & $53.5(26-71)$ & $60(34-77)$ & $57.0(26-78)$ \\
\hline $\begin{array}{l}\text { Ethnicity } \\
\text { White } \\
\text { Black } \\
\text { Other } \\
\text { BMl } \\
<30 \\
\geq 30\end{array}$ & $\begin{aligned} 53 & (82.8) \\
10 & (15.6) \\
1 & (1.6) \\
& \\
47 & (73.4) \\
12 & (26,6)\end{aligned}$ & $\begin{aligned} 56 & (81.2) \\
10 & (14.5) \\
3 & (4.3) \\
& \\
53 & (76.8) \\
16 & (23.2)\end{aligned}$ & $\begin{aligned} 40 & (87.0) \\
6 & (13.0) \\
0 & \\
37 & (80.40) \\
9 & (19.6)\end{aligned}$ & $\begin{aligned} 34 & (79.1) \\
7 & (16.3) \\
2 & (4.7) \\
& \\
32 & (74.4) \\
11 & (25.6)\end{aligned}$ & $\begin{aligned} 183 & (82.4) \\
33 & (14.9) \\
6 & (2.7) \\
169 & (76.1) \\
53 & (23.9)\end{aligned}$ \\
\hline $\begin{array}{l}\text { Host/L28B genotype, n (\%) } \\
\text { CC } \\
\text { CC } \\
\pi\end{array}$ & $\begin{array}{rr}7 & (10.9) \\
40 & (62.5) \\
17 & (26.6)\end{array}$ & $\begin{array}{ll}19 & (27.5) \\
35 & (50.7) \\
15 & (21.7)\end{array}$ & $\begin{array}{rr}7 & (15.2) \\
29 & (63.0) \\
10 & (21.7)\end{array}$ & $\begin{array}{rr}17 & (39.5) \\
20 & (46.5) \\
6 & (14.0)\end{array}$ & $\begin{aligned} 50 & (55.9) \\
124 & (55.9) \\
48 & (21.6)\end{aligned}$ \\
\hline $\begin{array}{l}\mathrm{CrCl}, \mathrm{mL} / \mathrm{min}, \mathrm{n}(\&) \\
\quad<50 \\
\quad \geq 50\end{array}$ & $\begin{aligned} 1 & (1.6) \\
63 & (98.4)\end{aligned}$ & $\begin{aligned} 0 & \\
69 & (100)\end{aligned}$ & $\begin{aligned} 1 & (2.2) \\
45 & (97.8)\end{aligned}$ & $\begin{aligned} 0 & \\
43 & (100)\end{aligned}$ & $\begin{aligned} 2 & (0.9) \\
220 & (99.1)\end{aligned}$ \\
\hline History of diabetes mellitus, $\mathrm{n}(\%)$ & $10(15.6)$ & $20(29.0)$ & $9(19.6)$ & $8(16.6)$ & $47(21.2)$ \\
\hline History of hypertension, $\mathrm{n}(\%)$ & $24(37.5)$ & $32(46.4)$ & $12(26.1)$ & $19(42.2))$ & $97(39.2)$ \\
\hline History of depression, $\mathrm{n}(\%)$ & $6(19.14)$ & $9(13.0)$ & $6(13.0)$ & $3(7.0)$ & $24(10.8)$ \\
\hline $\begin{array}{l}\text { Platelet count } \times 10^{9} / \mathrm{L} \\
\quad<90 \\
\quad \geq 90\end{array}$ & $\begin{array}{ll}10 & (15.6) \\
23 & (35.9) \\
41 & (64.1)\end{array}$ & $\begin{aligned} 6 & (8.7) \\
18 & (26.1) \\
51 & (73.9)\end{aligned}$ & $\begin{aligned} 2 & (4.3) \\
4 & (8.7) \\
42 & (91.3)\end{aligned}$ & $\begin{aligned} 3 & (7.0) \\
1 & (2.3) \\
42 & (97.7)\end{aligned}$ & $\begin{aligned} 21 & (9.5) \\
46 & (20.7) \\
176 & (79.3)\end{aligned}$ \\
\hline $\begin{array}{l}\text { Albumin, g/L } \\
\quad<35 \\
\quad \leq 35\end{array}$ & $\begin{array}{ll}11 & (17.2) \\
53 & (82.8)\end{array}$ & $\begin{array}{ll}11 & (15.9) \\
58 & (84.1)\end{array}$ & $\begin{aligned} 2 & (4.3) \\
44 & (95.7)\end{aligned}$ & $\begin{array}{r}0 \\
43 \quad(100)\end{array}$ & $\begin{array}{rr}24 & (10.8) \\
198 & (89.2)\end{array}$ \\
\hline $\begin{array}{l}\text { APRI score, median (range) } \\
\text { FIB-4 score, median (range) } \\
\text { HCV RNA level, IU/mL } \\
\quad<800,000 \\
\quad \geq 800,000\end{array}$ & $\begin{aligned} 2.4 & (0.5-15.2) \\
4.3 & (1-1-14.8) \\
13 & (20.3) \\
51 & (79.7)\end{aligned}$ & $\begin{aligned} 1.8 & (0.3-13.6) \\
4.0 & (0.9-20.8) \\
16 & (23.2) \\
53 & (76.8)\end{aligned}$ & $\begin{aligned} 1.0 & (0.3-6.7) \\
2.0 & (0.6-9.1) \\
9 & (19.6) \\
37 & (80.4)\end{aligned}$ & $\begin{aligned} 1.0 & (0.3-3.1) \\
2.1 & (0.5-6.1) \\
9 & (20.9) \\
34 & (79.1)\end{aligned}$ & $\begin{aligned} 1.4 & (0.3-15.2) \\
2.9 & (0.5-20.8) \\
47 & (21.2) \\
175 & (78.8)\end{aligned}$ \\
\hline Prior IFN treatment, $\mathrm{n}(\%)$ & $38(59.4)$ & $42(60.9)$ & $19(41.3)$ & $20(46.5)$ & $119(53.6)$ \\
\hline $\begin{array}{l}\text { Prior treatment response, } \mathrm{n}(\%) \\
\text { Null response } \\
\text { Null response } \\
\text { Partial response } \\
\text { Relapse } \\
\text { Relapse/breackthrough } \\
\text { IFN intolerant } \\
\text { Other }\end{array}$ & $\begin{aligned} 12 & (31.6) \\
7 & (88.4) \\
1 & (2.6) \\
8 & (21.1) \\
4 & (10.5) \\
1 & (2.6) \\
5 & (13.2)\end{aligned}$ & $\begin{aligned} 8 & (18.6) \\
12 & (27.9) \\
3 & (7.0) \\
14 & (32.6) \\
2 & (4.7) \\
1 & (2.3) \\
3 & (7.0)\end{aligned}$ & $\begin{array}{ll}1 & (5.3) \\
6 & (31.6) \\
1 & (5.3) \\
4 & (21.1) \\
4 & (21.1) \\
1 & (5.3) \\
2 & (10.5)\end{array}$ & $\begin{array}{ll}1 & (5.0) \\
1 & (5.0) \\
2 & (10.0) \\
8 & (40.0)) \\
2 & (10.0) \\
4 & (20.0) \\
2 & (10.0)\end{array}$ & $\begin{aligned} 22 & (18.3) \\
26 & (21.7) \\
7 & (5.8) \\
34 & (28.3) \\
12 & (10.0) \\
7 & (5.8) \\
-12 & (10.0)\end{aligned}$ \\
\hline
\end{tabular}

achieve SVR12, 1 patient experienced on-treatment virologic failure, 6 patients experienced post-treatment relapse and 1 GT1a-infected patient with undetectable HCV RNA at post-treatment Week 4 was subsequently lost to follow-up and had a missing HCV RNA value during the $\mathrm{SVR}_{12}$ assessment window. The SVR24 rate was $95.5 \%$ (212/222; 95\% CI, 91.9-97.5\%). The 2 additional patients who did not achieve SVR24 had missing HCV RNA values during the SVR24 assessment window (the patient with a missing HCV RNA value during the $\mathrm{SVR}_{12}$ assessment window also had a missing HCV RNA value during the SVR24 assessment window). No late relapses were documented between follow-up Week 12 and follow-up Week 24 , although two patients were lost to follow-up. 

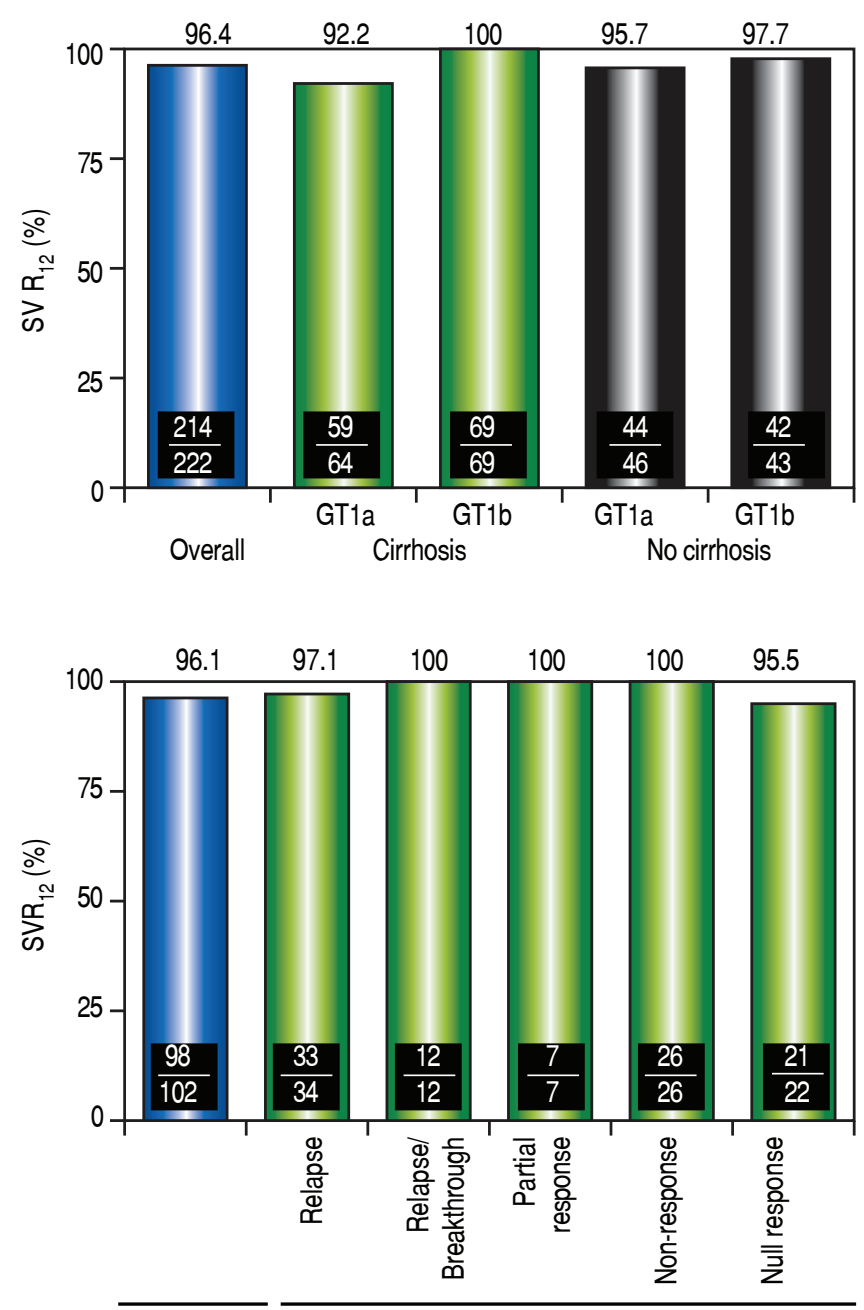

Naïve

Treatment-experienced

Figure 2. Sustained virologic response rates overall, and by HCV subtype, hepatic fibrosis status and previous response to pegIFN/RBV combination therapy. Definitions of responses to prior treatment with pegIFN/RBV: Relapse, undetectable HCV RNA at the end of treatment, but was detected during follow-up; Relapse/breakthrough, $\geq 1$ documented result of undetectable HCV RNA during treatment; Nonresponse, no documented undetectable HCV RNA results during treatment, or HCV RNA was detected at the end of treatment with insufficient data available to categorize the response as a relapse, breakthrough, partial response or null response; Partial response, $\geq 2-\log \mathrm{IU} / \mathrm{mL}$ decrease in HCV RNA by Week 12; Null response, < $1-\log \mathrm{IU} / \mathrm{mL}$ reduction in HCV RNA by Week.

The $\mathrm{SVR}_{12}$ rate was $99.1 \%(111 / 112)$ in patients with GT1b infection, and 93.6\% (103/110) in patients with GT1a infection. SVR12 was achieved in $96.2 \%$ (128/133) of cirrhotic patients and $96.6 \%(86 / 89)$ of noncirrhotic patients. Overall, 96.1\% (98/102) of treatment-naive patients, and $96.7 \%(116 / 120)$ of patients who had received prior IFNbased treatment achieved an $\mathrm{SVR}_{12}$ ( $\mathrm{p}=$ not significant, Figure 2B). Specifically, $\mathrm{SVR}_{12}$ was achieved by $97.1 \%$ in previous relapsers, $100 \%$ in patients with previous relapse/
Table 2, Baseline characterictics of patients who experienced virologic failure.

\begin{tabular}{|c|c|}
\hline Characterics & $\begin{array}{l}\text { Patients with virologic } \\
\text { failure }(n / N)\end{array}$ \\
\hline Male sex, $n(\%)$ & $5 / 7(71.4)$ \\
\hline Age, years, median (range) & $58(43-63)$ \\
\hline $\begin{array}{l}\text { HCV subtype, } n(\%) \\
\text { 1a } \\
1 \mathrm{~b}\end{array}$ & $\begin{array}{l}6 / 7(85.7) \\
1 / 7(14.3)\end{array}$ \\
\hline $\begin{array}{l}\text { Cirrhosis status } \\
\text { Non-cirrhotic } \\
\text { Cirrhotic }\end{array}$ & $\begin{array}{ll}3 / 7 & (42.9) \\
4 / 7 & (57.1)\end{array}$ \\
\hline $\begin{array}{l}\text { Host/L28B genotype, } n \% \\
\text { CC } \\
\text { CT }\end{array}$ & $\begin{array}{l}3 / 7(42.9) \\
4 / 7 \quad(57.1)\end{array}$ \\
\hline $\begin{array}{l}\text { Platelet count } \times 10^{9} / \mathrm{L} \\
\quad<90 \\
\quad \geq 90\end{array}$ & $\begin{array}{ll}2 / 7 & (28.6) \\
5 / 7 & (71.4)\end{array}$ \\
\hline $\begin{array}{l}\text { Albumin, } g / L \\
\quad<35 \\
\quad \geq 35\end{array}$ & $\begin{array}{l}1 / 7(14.4) \\
6 / 7(85.7)\end{array}$ \\
\hline APRI score, median (range) & $1.46(0.63-4.62)$ \\
\hline FIB-4, median (range) & $3.33(1.44-9.71)$ \\
\hline $\begin{array}{l}\text { HCV RNA level, IU/mL } \\
\quad<800,00 \\
\quad \geq 800,00\end{array}$ & $\begin{array}{l}1 / 7(14.3) \\
6 / 7 \quad(85.7)\end{array}$ \\
\hline Prior IFN treatment, $\mathrm{n}(\%)$ & $4 / 7(57.1)$ \\
\hline $\begin{array}{l}\text { Prior treatment response, } \mathrm{n} \text { ( } \\
\text { Null response } \\
\text { Relapse } \\
\text { Other }\end{array}$ & $\begin{array}{ll}1 / 4 & (25.0) \\
2 / 4 & (25.0) \\
1 / 4 & (25.0)\end{array}$ \\
\hline
\end{tabular}

breakthrough, partial response or nonresponse, and 95.5\% in patients with a prior null response to IFN/RBV or pegIFN/RBV combination therapy.

The baseline characteristics of the patients who experienced virologic failure are presented in table 2 .

\section{Resistance-associated substitutions in patients with virologic failure}

Seven of the 8 patients who did not achieve $\mathrm{SVR}_{12}$ experienced virologic failure. Six individuals (5 infected with GT1a, 1 with GT1b) experienced relapse during followup, and 1 individual (GT1a-infected) experienced ontreatment virologic failure (breakthrough at Week 12).

Substitutions at resistance-associated amino acid positions in NS3, NS5A, or NS5B in patients who experienced virologic failure are shown in table 3 . NS3 substitutions were not detected at baseline in any patients, but were detected at the time of virologic failure in 5 patients. NS5A substitutions were detected in 3 patients at baseline 
and in all 7 patients at the time of virologic failure. NS5B substitutions were detected in 2 patients at baseline and in 4 patients at the time of virologic failure. The most common treatment-emergent substitutions were R155K and D168V in NS3, M28T and Q30R in NS5A, and C316Y, M414I, G554D, and S556G in NS5B.

\section{Safety}

Among 222 patients in the safety population, 78.4\% (174/ 222) patients experienced at least 1 TEAE, and $2.7 \%(6 / 222)$ patients experienced at least 1 serious AE (SAE) (Table 4). One $(0.5 \%)$ cirrhotic patient assigned to 3 -DAA plus RBV

Table 3. Patients with virologic failure: NS, NS5A, and NS5B substitutions at baseline at the time of virologic failure.

\begin{tabular}{|c|c|c|c|c|c|c|c|c|c|}
\hline \multirow{3}{*}{$\begin{array}{l}\text { Genotipe and } \\
\text { cirrhosis } \\
\text { status }\end{array}$} & \multirow{3}{*}{$\begin{array}{l}\text { Treatment } \\
\text { status }\end{array}$} & \multirow{3}{*}{$\begin{array}{l}\text { Treatment } \\
\text { duratioin, } \\
\text { weeks }\end{array}$} & \multirow{3}{*}{$\begin{array}{l}\text { Reason for } \\
\text { virologic } \\
\text { failure }\end{array}$} & \multicolumn{6}{|c|}{ Substitutions detected at basiline and at the time of virologic failure } \\
\hline & & & & \multicolumn{2}{|c|}{ NS3 } & \multicolumn{2}{|c|}{ NS5A } & \multicolumn{2}{|c|}{ NS5B } \\
\hline & & & & $\mathrm{BL}$ & VF & $\mathrm{BL}$ & VF & $\mathrm{BL}$ & VF \\
\hline \multirow[t]{4}{*}{ GT1a, cirrhotic } & Naïve & 12 & Relapse & None & $\begin{array}{l}\text { V36M, Q80L, } \\
\text { R155K, } \\
\text { D168V }\end{array}$ & $\begin{array}{l}\text { M28V, } \\
\text { Q30R }\end{array}$ & $\begin{array}{l}\text { M28V, } \\
\text { Q30 }\end{array}$ & None & M414, S556G \\
\hline & Experienced & 12 & Relapse & None & D168V & None & $\begin{array}{l}\text { M28T } \\
\text { Q554D }\end{array}$ & None & None \\
\hline & Eperienced & 24 & Relapse & None & R155K & None & Q30R & $\mathrm{Y} 448 \mathrm{H}$ & Y448H, G554D \\
\hline & Naïve & 12 & Breaktrough & None & $\begin{array}{l}\text { R155K } \\
\text { Y93H }\end{array}$ & Q30H & Q30R & None & None \\
\hline \multirow{2}{*}{$\begin{array}{l}\text { GT1a, } \\
\text { noncirrhotic }\end{array}$} & Experienced & 12 & Relapse & None & None & None & Q30R & None & C316Y, S5556G \\
\hline & Naïve & 12 & Relapse & None & R155K, & None & Q30R & None & None \\
\hline $\begin{array}{l}\text { GT1B, } \\
\text { noncirrhotic }\end{array}$ & Experienced & 12 & Relapse & None & None & Y93H & Y93H & C316N & C316B, M4114 \\
\hline
\end{tabular}

Amino acid positions included in the analysis of virus from patients with GT1a infection: $36,43,55,56,80,155,156,168$ in NS3; 24, 28, 29, 30, 31, 32, 58, 62, 92, 93 in NS5A; 316, 414, 446, 448, 451, 553, 554, 555, 556, 558, 559, 561 in NS5B. Amino acid positions included in analysis of virus from patients with GT1b infection: 55, 56, 155, 156, 168 in NS3; 24, 28, 29, 30, 31, 32, 58, 62, 92, 93 in NS5A; 316, 368, 411, 445, 448, 553, 556, 558, 559 in NS5B.

Table 4. Adverse events.

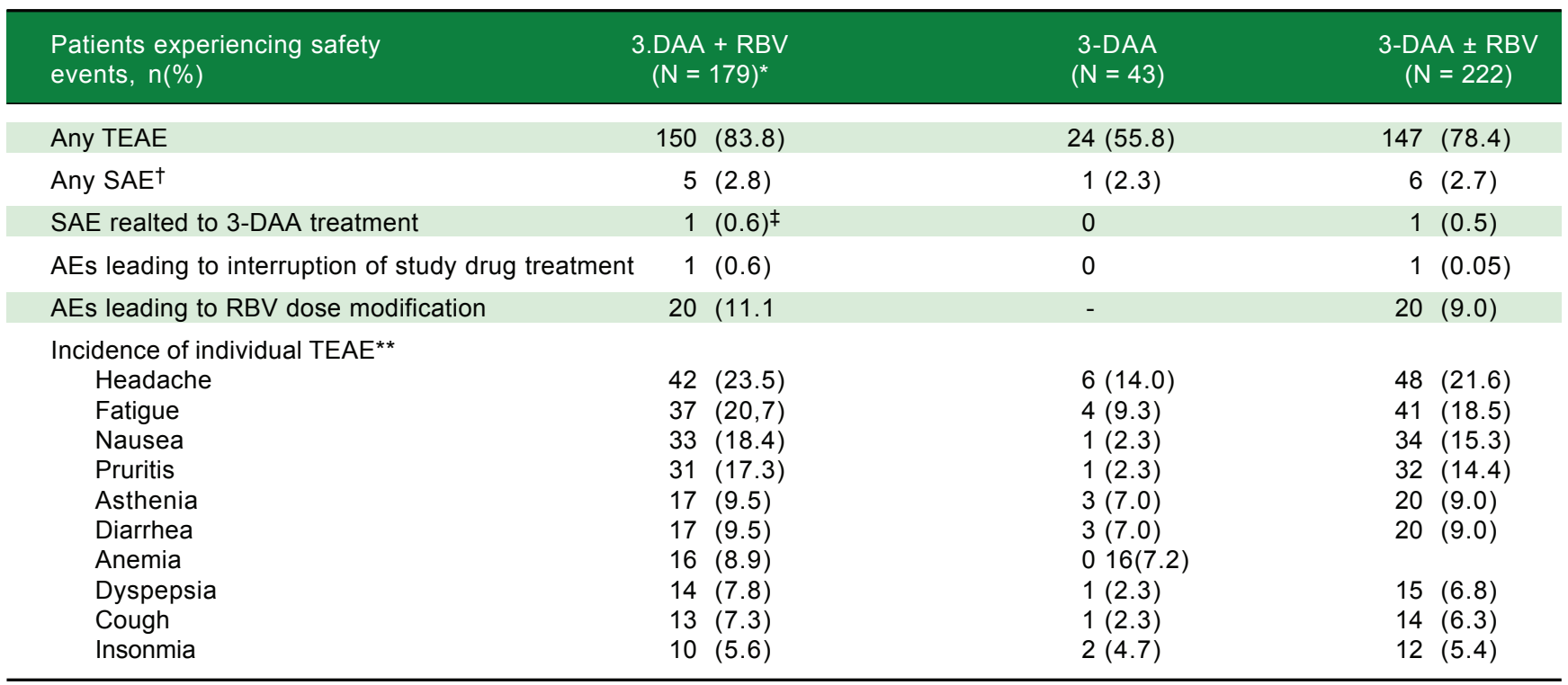

AE: adverse event. SAE: serious AE. TEAE: treatment-emergent AE. * Includes cirrhotic and non-cirrhotic patients receiven 3-DAA + RBV for 12 weeks, and cirrhotic patients receiving 3-DAA + RBV for 24 weeks. ${ }^{\dagger}$ SAES reported during treatment included mestastic lung adenocarcinoma, esophageal and renal failure an transient ischemic attack in one patient. ${ }^{\ddagger}$ Hepatic failure. ${ }^{* *} A E s$ with an incidence $\geq 5 \%$. 
discontinued study drug treatment after Week 11 (Day 77) because of a TEAE (Grade 2 ascites, assessed by the investigator as having no reasonable possibility of being related to study drug), which started 5 days prior to discontinuation of study drug and resolved 28 days later. This patient achieved SVR 12 , but not SVR24 due to missing data, and subsequently developed HCC and died (see description below). TEAEs reported with an incidence $\geq 10 \%$ during treatment included headache $(21.6 \%)$, fatigue $(18.5 \%)$, nausea $(15.3 \%)$ and pruritus (14.4\%).

Six patients $(2.7 \%)$ experienced SAEs during the study (Table 4). A 65-year-old male patient with cirrhosis experienced hepatic decompensation starting at post-treatment Day 10 that was considered to be possibly related to treatment with both the 3-DAA regimen and RBV in the opinion of the investigator. This patient was classified as Child-Pugh B at screening, which was considered a protocol deviation. This patient also had a presumptive diagnosis of spontaneous bacterial peritonitis at this time (aerobic and anaerobic cultures of ascitic fluid were negative), and treatment with intravenous ceftriaxone was initiated. The event of hepatic failure was considered resolved 20 days after the last dose of study drug was administered. Additionally, a 49-year-old male patient without cirrhosis experienced renal failure and a transient ischemic attack on treatment Day 22. Both SAEs in the latter individual were considered to be possibly related to treatment with RBV, but not the 3-DAA regimen, in the opinion of the investigator. All other SAEs were not related to treatment in the opinion of the investigator.

The overall incidence of AEs and SAEs and the incidence of certain AEs were numerically higher in patients assigned to receive RBV than in patients assigned to the 3DAA regimen alone, although AEs were generally of mild to moderate severity and clinically manageable (Table 4). In particular, anemia was not reported as an AE in any patient assigned to the RBV-free regimen, compared with 8.9\% (16/ 179) of patients receiving the 3-DAA regimen with RBV.

Adverse events leading to RBV dose modification (as recommended in the RBV prescribing information) occurred in $20(9.0 \%)$ of patients. These events included anemia (8 subjects), decreased hemoglobin (6 subjects), fatigue (4 subjects), asthenia, cough (2 subjects each), and decreased creatinine clearance, hypotension, pruritus, rash, renal failure, and respiratory tract infection (1 subject each).

Three $(1.4 \%)$ deaths occurred during the post-treatment follow-up period $>4$ months after taking the last dose of study drugs. One death due to HCC occurred 22 weeks post-treatment in a 54-year-old male patient with cirrhosis who had no evidence of HCC on baseline screening examinations; one death due to sepsis and hepatic decompensation occurred 21 weeks post treatment following complications related to total hip arthroplasty in a 59-year-old female patient with cirrhosis; and one death due to septicemia occurred 36 weeks post treatment in a 64-year-old male patient with diabetic vasculopathy, who developed an Acinetobacter infection after foot trauma. None of the three deaths were considered to be related to study drug treatment in the opinion of the investigator.

No patients experienced a Grade 3 or greater increase in ALT level during the study. One patient experienced a Grade 3 decrease in hemoglobin and one patient experienced a Grade 4 decrease in hemoglobin during 12 weeks of treatment with the 3-DAA + RBV regimen.

Twelve patients (5.4\%) experienced Grade 3 elevations in total bilirubin concentration during treatment. All of these patients had cirrhosis and were assigned to the 3DAA + RBV regimen. No patients experienced a Grade 4 increase in this parameter during the study.

\section{DISCUSSION}

The efficacy and safety of OBV/PTV/r + DSV (3-DAA) with and without RBV have been demonstrated in several previous large international phase 3 studies in patients with GT1 infection. ${ }^{10-15}$ The present study confirms the efficacy and safety profile of the 3-DAA regimen in Brazilian patients with advanced liver fibrosis including compensated cirrhosis, thrombocytopenia (platelets as low as $25,000 / \mathrm{mm}^{3}$ ), hypoalbuminemia (albumin as low as $2.8 \mathrm{~g}$ / $\mathrm{dL})$, and moderate renal dysfunction $(\mathrm{CrCl}$ as low as 30 $\mathrm{ml} / \mathrm{min}$ ). Overall, $96.4 \%$ of the patients in the ITT population achieved an $\mathrm{SVR}_{12}$. Efficacy rates were consistently high among GT1a-infected patients with (92.2\%) and without (95.7\%) cirrhosis, and among GT1b-infected patients with $(100 \%)$ and without $(97.7 \%)$ cirrhosis. Importantly, only 7 out of 222 patients (3.2\%) experienced virologic failure when treated with the 3-DAA regimen. Furthermore, the 3-DAA regimen produced high response rates regardless of previous treatment history or advanced fibrosis staging. These results corroborate the findings of another clinical trial that explored the need for RBV among GT1b-infected patients with cirrhosis. In the TURQUOISE-III trial, $60 \mathrm{HCV}$ GT1b-infected patients with cirrhosis were treated with the 3-DAA regimen without RBV. ${ }^{15}$ All 60 patients $(100 \%)$ achieved an SVR ${ }_{12}$, indicating that RBV is not required to maximize

In resistance analyses, substitutions at resistance-associated amino acid positions in NS3, NS5A and or NS5B were assessed at baseline and at the time of virologic failure in the seven patients (6 GT1a, 1 GT1b) who experienced virologic failure. The small number of patients who failed to achieve $\mathrm{SVR}_{12}$, and the overall pattern of resistance observed in these individuals suggests that there was no correlation between the baseline resistance profile and the substitutions that emerged during treatment. 
Treatment with the 3-DAA regimen was well tolerated in the present trial and the results of the safety analysis are consistent with that reported previously in patients with advanced hepatic fibrosis. ${ }^{14,15}$ In a population that included only patients with advanced liver fibrosis, no new safety signals were reported during the study. One patient discontinued treatment because of a TEAE (ascites that evolved into a diagnosis of HCC and death), and three patients died during follow-up ( $>4$ months after the last dose of study drug treatment); however, none of these events was considered to be associated with study drug treatment. The incidence of AEs such as fatigue, nausea, pruritus and anemia were consistently higher in patients who received an RBV-containing regimen than in those receiving the 3-DAA regimen alone. These AEs are likely associated with RBV as they have previously been shown to be reported at a higher frequency among patients randomized to the 3-DAA regimen with RBV, compared to patients randomized to the 3-DAA regimen alone, ${ }^{11,13}$ and are also associated with RBV according to the drug package insert. ${ }^{16}$ Overall, the regimen was also well tolerated in patients with a wide range of comorbid conditions, such as hypertension, diabetes mellitus, depression, hypothyroidism, hypoalbuminemia, thrombocytopenia and moderate renal dysfunction. Anemia was not reported in patients assigned to the RBV-free regimen and the incidence of anemia was $<10 \%$ in patients who received RBV. Paritaprevir is a known inhibitor of the OAT1B1 bilirubin transporter, which is likely responsible for the isolated and largely asymptomatic increases in bilirubin serum levels that were observed in the present study.

A notable strength of the study is the inclusion of a large proportion of patients with advanced liver fibrosis (F3/F4) and comorbid conditions, such as thrombocytopenia, and moderate renal dysfunction. It must be emphasized however, that patients with a history of decompensated cirrhosis were not eligible for this study, and that the 3-DAA regimen should be avoided in patients with decompensated cirrhosis or a previous history of decompensation. Since patients with advanced fibrosis and a wide range of comorbidities are eligible for treatment under Brazil's universal health program, the high overall efficacy and good tolerability demonstrated in this trial could be generalized to the population in which treatment is recommended in Brazil. The inclusion of only patients with advanced fibrosis also limits the generalizability of the results to a broader population that includes patients with stage F1 and F2 fibrosis; however, other studies have focused on treatment of patients with minimal liver fibrosis, or the full spectrum of fibrosis stages. ${ }^{10-13,17}$

This trial has certain limitations. The open-label design of the study is unlikely to have biased the reporting of efficacy results because HCV RNA is an objective laboratory assessment; however, when combined with the lack of control group it could have introduced bias in the reporting of safety events. However, the 3-DAA plus RBV regimen was well tolerated in two placebo-controlled trials in which the most common adverse events were fatigue, headache, and nausea, which is consistent with the results of the present trial. ${ }^{10,12}$

At the time the study was planned and initiated, few DAAs were approved and available for use in Brazil. IFNbased regimens could have been used as a comparator, however, it would have been difficult to blind patients to treatment with IFN-based regimens and patients may not have been willing to accept IFN-based therapy in a comparative trial because of the poor tolerability and low $\mathrm{SVR}_{12}$ rates. The study was also not powered for comparisons among subgroups of patients with different fibrosis staging or prior treatment history.

In conclusion, the results of this trial confirm that treatment with the 3-DAA regimen with RBV, or without RBV is safe and can be an effective option for the treatment of chronic HCV GT1 infection in the Brazilian patient population with bridging fibrosis or cirrhosis (METAVIR F3/4). In particular, the 3-DAA regimen without RBV is suitable for GT1b-infected patients without cirrhosis, whereas the 3-DAA regimen with RBV is required to maximize efficacy in GT1b patients with cirrhosis and all GT1a patients.

\section{ABBREVIATIONS}

- AE: adverse event.

- ALT: alanine aminotransferase.

- APRI: AST to platelet ratio index.

- AST: aspartate aminotransferase.

- DAA: direct-acting antiviral agent.

- DSV: dasabuvir.

- EOT: end of treatment.

- GT1b: HCV genotype 1b.

- HCV: hepatitis C virus.

- LLOQ: lower limit of quantification.

- OBV: ombitasvir;

- PTV/r: paritaprevir coadministered with ritonavir.

- RBV: ribavirin.

- SAE: serious AE.

- SVR: sustained virologic response.

- TEAE: treatment-emergent adverse events.

- ULN: upper limit of normal.

\section{CONFLICT OF INTEREST}

The authors declares that there is no conflict of interest regarding the publication of this article. 


\section{FINANCIAL SUPPORT}

AbbVie provided funding for this study and participated in design, research, data collection, interpretation of data, writing, reviewing and approving of the publication.

\section{FINANCIAL DISCLOSURE}

- MG Pessoa: Research grants: AbbVie, and Janssen; Advisory Board participation and speaker for: AbbVie, Alexion, Gilead, BMS, Janssen, and MSD.

- JVR Madruga: participation in clinical studies: AbbVie.

- K Alves, SA Lari, L Liu, R Tripathi, T Pilot-Matias, DE Cohen, NS Shulman: employees of AbbVie and may hold stock or stock options.

- EP Nunes: Speaker for, Advisory Board participation in, and Research grant from AbbVie.

- H Cheinquer: Research grants: AbbVie, BMS, Gilead, MSD; Advisory Board participation: AbbVie, BMS, Gilead, MSD; Speaker for: AbbVie, BMS, Gilead, MSD, Janssen.

- CE Brandão-Mello: Speaker for and Consultant to AbbVie, Merck, Gilead, Janssen and BMS; Member: National and State of Rio de Janeiro Committee of Viral Hepatitis and Liver Diseases.

- CM Correa: Participation in clinical studies: AbbVie.

- ML Ferraz: Participation in clinical studies: AbbVie.

- P Ferreira: Advisory Board participation: AbbVie; Scientific Support: AbbVie.

- MR Álvares-da-Silva: Research grants: AbbVie, Gilead, MSD, Fiocruz, Eisai, and Janssen; Advisory Board participation: AbbVie, Bayer, Gilead, and MSD. Speaker for: AbbVie, Bayer, Gilead, MSD, and Janssen; Member: Ministry of Health Committees on Hepatitis C and Liver Transplant.

- HCS Moraes: Participation in clinical studies: AbbVie.

- E de Araujo: Participation in clinical studies: AbbVie.

- J Furtado: Participation in clinical studies: AbbVie.

- R Parana: Participation in clinical studies: AbbVie.

- G Silva: Advisory Board participation and Scientific Support: AbbVie.

- A Martinelli: Participation in clinical studies: AbbVie.

\section{ACKNOWLEDGMENT}

Medical writing assistance was provided by Blair Jarvis MSc, ELS of Medical Expressions, funded by AbbVie.

\section{REFERENCES}

1. Castro R, Perazzo H, Grinsztejn B, Veloso VG, Hyde C. Chronic Hepatitis C: An Overview of Evidence on Epidemiology and Management from a Brazilian Perspective. Int $J$ Hepatol 2015; 2015: 852968.
2. Pereira LM, Martelli CM, Moreira RC, Merchan-Hamman E, Stein AT, Cardoso MR, Figueiredo GM, et al. Prevalence and risk factors of Hepatitis C virus infection in Brazil, 2005 through 2009: a cross-sectional study. BMC Infect Dis 2013; 13: 60-2334-13-60.

3. Amaku M, Burattini MN, Coutinho FA, Lopez LF, Mesquita F, Naveira MC, Pereira GF, et al. Estimating the Size of the HCV Infection Prevalence: A Modeling Approach Using the Incidence of Cases Reported to an Official Notification System. Bull Math Biol 2016; 78: 970-90.

4. Brazilian Ministry of Health announces National Plan for Elimination of Hepatitis C by 2030 with the offer of treatment for all. Presentation by Ricardo Barros, Minister of Health. World Hepatitis Summit 2017. Sao Paulo, Brazil, 1-3 November 2017. Available at http://portalarquivos2.saude.gov.br/images/pdf/2017/novembro/01/Evento-Hepatites-SP-com-edicaoIngles.pdf.

5. Protocolo clínico e diretrizes terapêuticas para hepatite $\mathrm{C}$ e coinfecções. Ministério da Saúde, Secretaria de Vigilancia em Saude, Departamento de Vigilancia, Prevencao e Controle das Infeccoes Sexualmente Transmissiveis, do HIV/ Aids e das Hepatites Virais, Brasília. 2017. Available at http://www.aids.gov.br/pt-br/pub/2017/protocolo-clinicoe-diretrizes-terapeuticas-para-hepatite-c-e-coinfeccoes Accessed November 14, 2017.

6. Polaris Observatory HCV Collaborators. Global prevalence and genotype distribution of hepatitis $C$ virus infection in 2015: a modelling study. Lancet Gastroenterol Hepatol 2017; 2: 161-76.

7. AASLD-IDSA Guidance Panel. HCV Guidance: Recommendations for Testing, Managing, and Treating Hepatitis C. Available at: https://www.hcvguidelines.org/ Accessed November 14, 2017.

8. Omata M, Kanda T, Wei L, Yu ML, Chuang WL, Ibrahim A, Lesmana CR, et al. APASL consensus statements and recommendation on treatment of hepatitis C. Hepatol Int 2016; 10: 702-26.

9. European Association for the Study of the Liver (EASL). EASL Recommendations on Treatment of Hepatitis C 2016. J Hepatol 2017; 66: 153-94.

10. Feld JJ, Kowdley KV, Coakley E, Sigal S, Nelson DR, Crawford D, Weiland O, et al. Treatment of HCV with ABT-450/rombitasvir and dasabuvir with ribavirin. N Engl J Med 2014; 370: 1594-603.

11. Ferenci $P$, Bernstein D, Lalezari J, Cohen D, Luo Y, Cooper C, Tam E, et al. ABT-450/r-ombitasvir and dasabuvir with or without ribavirin for HCV. N Engl J Med 2014; 370: 1983-92.

12. Zeuzem S, Jacobson IM, Baykal T, Marinho RT, Poordad F, Bourliere M, Sulkowski MS, et al. Retreatment of HCV with ABT-450/r-ombitasvir and dasabuvir with ribavirin. $N$ Engl J Med 2014; 370: 1604-14.

13. Andreone P, Colombo MG, Enejosa JV, Koksal I, Ferenci $P$, Maieron A, Mullhaupt B, et al. ABT-450, ritonavir, ombitasvir, and dasabuvir achieves $97 \%$ and $100 \%$ sustained virologic response with or without ribavirin in treatment-experienced patients with HCV genotype $1 \mathrm{~b}$ infection. Gastroenterology 2014; 147: 359-65.

14. Poordad F, Hezode C, Trinh R, Kowdley KV, Zeuzem S, Agarwal K, Shiffman ML, et al. ABT-450/r-ombitasvir and dasabuvir with ribavirin for hepatitis $\mathrm{C}$ with cirrhosis. $N$ Engl J Med 2014; 370: 1973-82.

15. Feld JJ, Moreno C, Trinh R, Tam E, Bourgeois S, Horsmans $\mathrm{Y}$, Elkhashab M, et al. Sustained virologic response of $100 \%$ in HCV genotype $1 \mathrm{~b}$ patients with cirrhosis receiving ombitasvir/paritaprevir/r and dasabuvir for 12 Weeks. J Hepatol 2016; 64: 301-7. 
16. Copegus (ribavirin) tablets. Prescribing Information. Genentech USA, Inc. South San Francisco, CA, USA.

17. Lawitz E, Makara M, Akarca US, Thuluvath PJ, Preotescu LL, Varunok P, Morillas RM, et al. Efficacy and Safety of Ombitasvir, Paritaprevir, and Ritonavir in an Open-Label Study of Patients With Genotype 1b Chronic Hepatitis C Virus Infection With and Without Cirrhosis. Gastroenterology 2015; 149: $971-80$.
Correspondence and reprint request:

Mario G. Pessoa, M.D.

Divisão de Gastroenterologia e Hepatologia Clinica, Departamento de Gastroenterologia, Hospital das Clinicas HCFMUSP, Faculdade de Medicina, Universidade de São Paulo

Avenida Dr. Enéas de Carvalho Aguiar 255, 9o andar Sala 9117 São Paulo - SP. 05403-000 Brazil

Tel.: +55 11 2661-3340

E-mail: mgpessoa@usp.br 